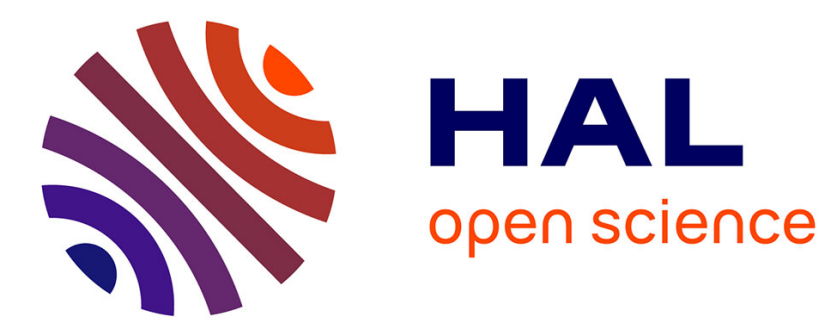

\title{
TOUGHNESS AND HEAT TREATMENT. RELATIONSHIP IN A 2091 ALUMINIUM ALLOY
}

L. Hautefeuille, R. Rahouadj, Y. Barbaux, M. Clavel

\section{To cite this version:}

L. Hautefeuille, R. Rahouadj, Y. Barbaux, M. Clavel. TOUGHNESS AND HEAT TREATMENT. RELATIONSHIP IN A 2091 ALUMINIUM ALLOY. Journal de Physique Colloques, 1987, 48 (C3), pp.C3-669-C3-675. 10.1051/jphyscol:1987377 . jpa-00226608

\section{HAL Id: jpa-00226608 https://hal.science/jpa-00226608}

Submitted on 1 Jan 1987

HAL is a multi-disciplinary open access archive for the deposit and dissemination of scientific research documents, whether they are published or not. The documents may come from teaching and research institutions in France or abroad, or from public or private research centers.
L'archive ouverte pluridisciplinaire HAL, est destinée au dépôt et à la diffusion de documents scientifiques de niveau recherche, publiés ou non, émanant des établissements d'enseignement et de recherche français ou étrangers, des laboratoires publics ou privés. 


\title{
TOUGHNESS AND HEAT TREATMENT, RELATIONSHIP IN A 2091 ALUMINIUM ALLOY
}

\author{
L. haUtefFeullle, R. RAhouadj, Y. Barbaux ${ }^{*}$ and M. Clavel \\ Université de Technologie de Compiègne, CNRS-UA 849, B.P. 233, \\ Rue $P$. de Roberval, F-60206 Compiègne Cedex, France \\ *Aérospatiale, Laboratoire Central, 12, Rue Pasteur. \\ F-92152 Suresnes Cedex, France
}

\begin{abstract}
The 2091 alloy was tested to determine toughness levels with respect to heat treatment. A drastic decrease in fracture toughness was observed as a function of heat treatment. The occurence of such a toughness drop was clearly related to fracture modes : Transgranular and intergranular precipitation and deformation modes were studied. The loss of grain boundary strength could be explained by the precipitation of the quasi crystaline phase T2
\end{abstract}

\section{IHTRODUCTION}

Among the different aluminium lithium alloys developed the CP274 (2091) was chosen for this study. This material in the as-received state presents an adequate composition to provide high mechanical resistance and ductility. The composition of this alloy is shown in table 1. The as recelved alloy was in the form of rolled sheet 1.6 or $3 \mathrm{~mm}$ thick, solutionized at $525^{\circ} \mathrm{C}$, water quenched followed by $2.5 \%$ stretching and then aged at room temperature for 48 hours(T3). This material is fully recrystallized with a mean grain diameter of $35 \mu \mathrm{m}$.
Element
Li
$\mathrm{Cu}$
$\mathrm{Mg}$
$\mathrm{Zr}$
$\mathrm{Fe} \quad \mathrm{Si}$
Si
Ti
A1
Veight $(\%)$
1.9
Table. 1: AIloy composition.

$\begin{array}{cc}\text { Ti } & \text { Al } \\ 0.02 & 94.72\end{array}$

In this study the following heat treatments (H. I) were used:

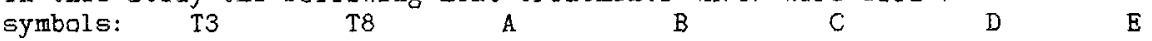

H. T : as quenched $12 \mathrm{~h} 135^{\circ} \mathrm{C} \quad 24 \mathrm{~h} 150^{\circ} \mathrm{C} \quad 100 \mathrm{~h} 150^{\circ} \mathrm{C} \quad 24 \mathrm{~h} 170^{\circ} \mathrm{C} 100 \mathrm{~h} 170^{\circ} \mathrm{C} \quad 20 \mathrm{~h} 190^{\circ} \mathrm{C}$

\section{EXPERIMENTAL RESULTS}

- Mechanical behaviour

The complete results obtained from tensile tests and from toughness tests are gathered in table 2 for the min H.I.. It may be noted that an increase in yield stress and ultimate stress occurs as the H.T, approaches the peak aged and also that a drastic decrease in toughness is observed for the H.T. C. The toughness tests were conducted on CCT specimens(w=200mm)following the ASTM E561 specification.

$\begin{array}{cccccc}\begin{array}{c}\text { AGING } \\ \text { TREATMENT }\end{array} & \text { Y.S. (MPa) } & \text { U.T.S. (MPa) } & \begin{array}{c}\text { ELONG. }(\%) \\ \text { Emax }\end{array} & \text { Ko (MPa) } & \text { H. } \\ \text { T3 } & 298 & 407 & 18.7 & 82 & 120 \\ \text { T8 } & 335 & 438 & 17 & 85 & 129.4 \\ \text { A } & 367 & 473 & 12 & 83 & 141.8 \\ \text { C } & 387 & 481 & 10 & 35 & 155.3\end{array}$

- Fracture modes

Table.2: Tensile and toughness results

The fracture associated with tensfle tests remains essentially transgranular for H. T. T3 and T8, the fracture mode becoming intergranular for $H . T$. $A$ and $C$. The fracture modes in toughness tests remain in the unstable propagation part. It may be noted however that H.T. A exhibits transgranular fracture mode in the stable propagation part. Plastic deformation is clearly revealed by straight striations on fractured grain boundaries.

- Transgranular precipitation

Aluminium lithium alloys containing a large amount of copper and magnesium are characterized $[1]$ by the precipitation of $\mathrm{Al} 11$ and $\mathrm{Al}$. $\mathrm{CuM} 8$ phases. For each $H . T$. we have measured the average $\delta^{\prime}$ diameter; all the results are plotted in fig. 1 
During the H.T.T3 and T8 we did not encounter $S^{\prime}$ phase. Nevertheless small GPB zones could not be detected with classical transmission electron microscopy (T.E.M.). GPB zones could induce small [100) direction streaks on the 〈001) diffraction patterns. In the as received condition (I3) this material exhibits a large number of helical or loop dislocations induced by quenching. A large quantity of linear defects could favour the heterogeneous precipitation of S!.Fig.2 shows the precipitation of $S^{\prime}$ phase on dislocations and loops, homogeneous precipitation is also encountered. A summary of our observations about $S^{\prime}$ phase for all the H.I. is shown in table 3 in which diffraction patterns are also included.
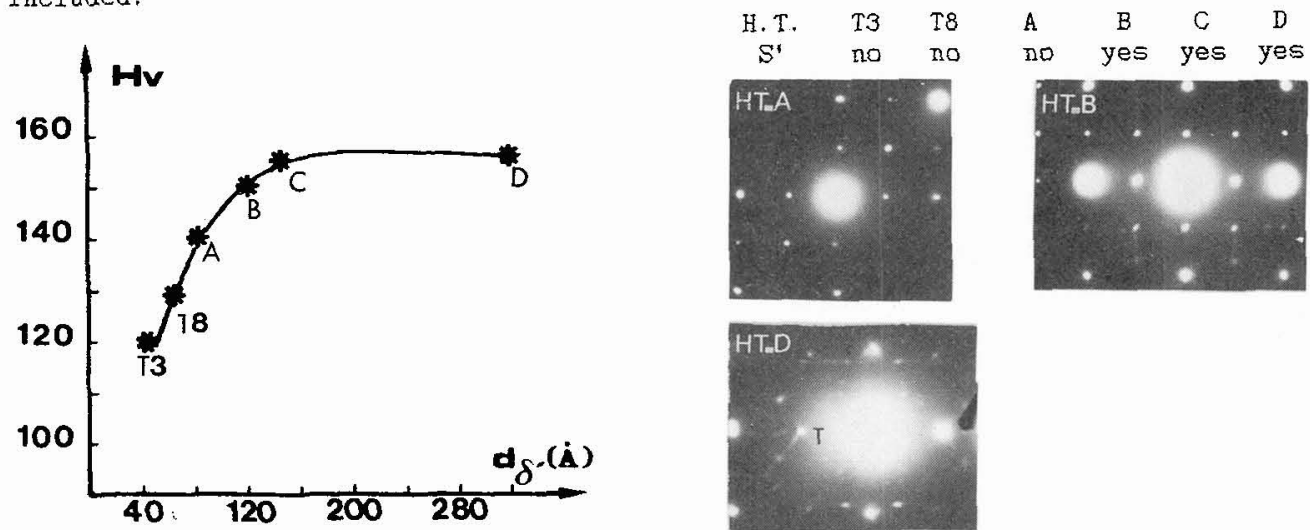

Figure 1:Hardness versus $\delta^{\prime}$ diameter H. I. are included.

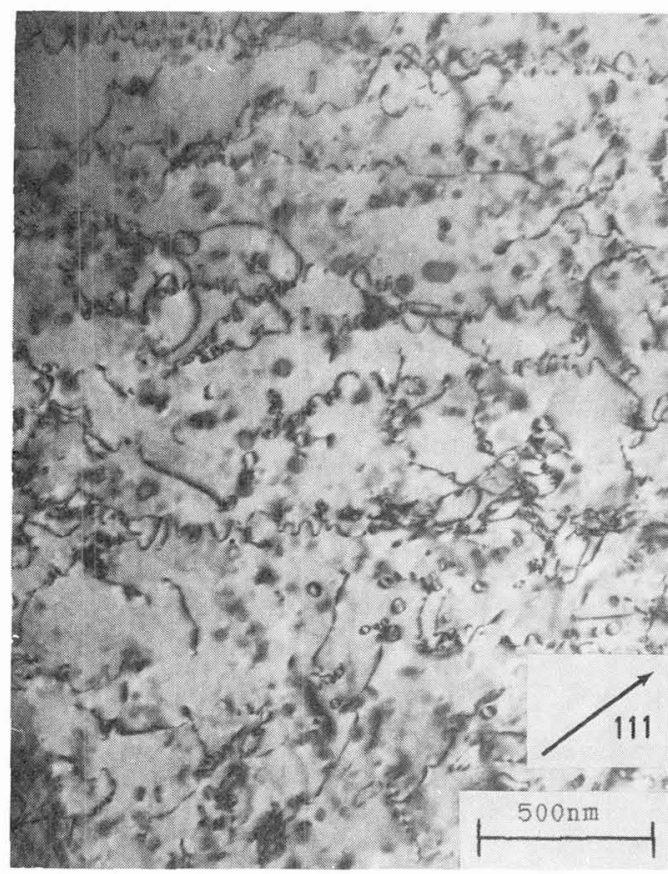

Figure 2; T.E.M. a)Bright field H.T. T3
Table 3: $S^{\prime}$ precipitation various H.T. diffraction patterns are included.

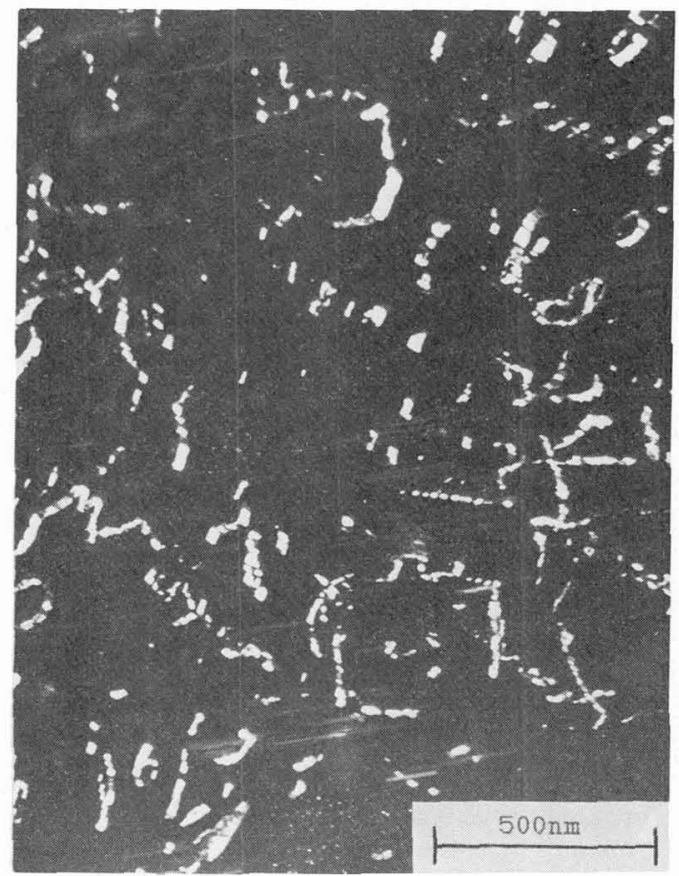

b) Dark field and pattern H,T. E 
- Intergranular preotpitation

The structural study of grain boundaries for T3 and T8 H.T. shows that boundaries remin free of precipitation as 11 lustrated in fig.3. Observations relative to H. T. $A$ and $C$ are shown in fig, 4 where intergranular precipitates are clearly apparent. The crystallographic identification is shown on fig. 5 where the typical five fold symetry [2] of quasi crystalline phase is evidenced for H.T. C. It may be noted that there is no significant precipitate free zone for H.T.T3,T8, A and C.
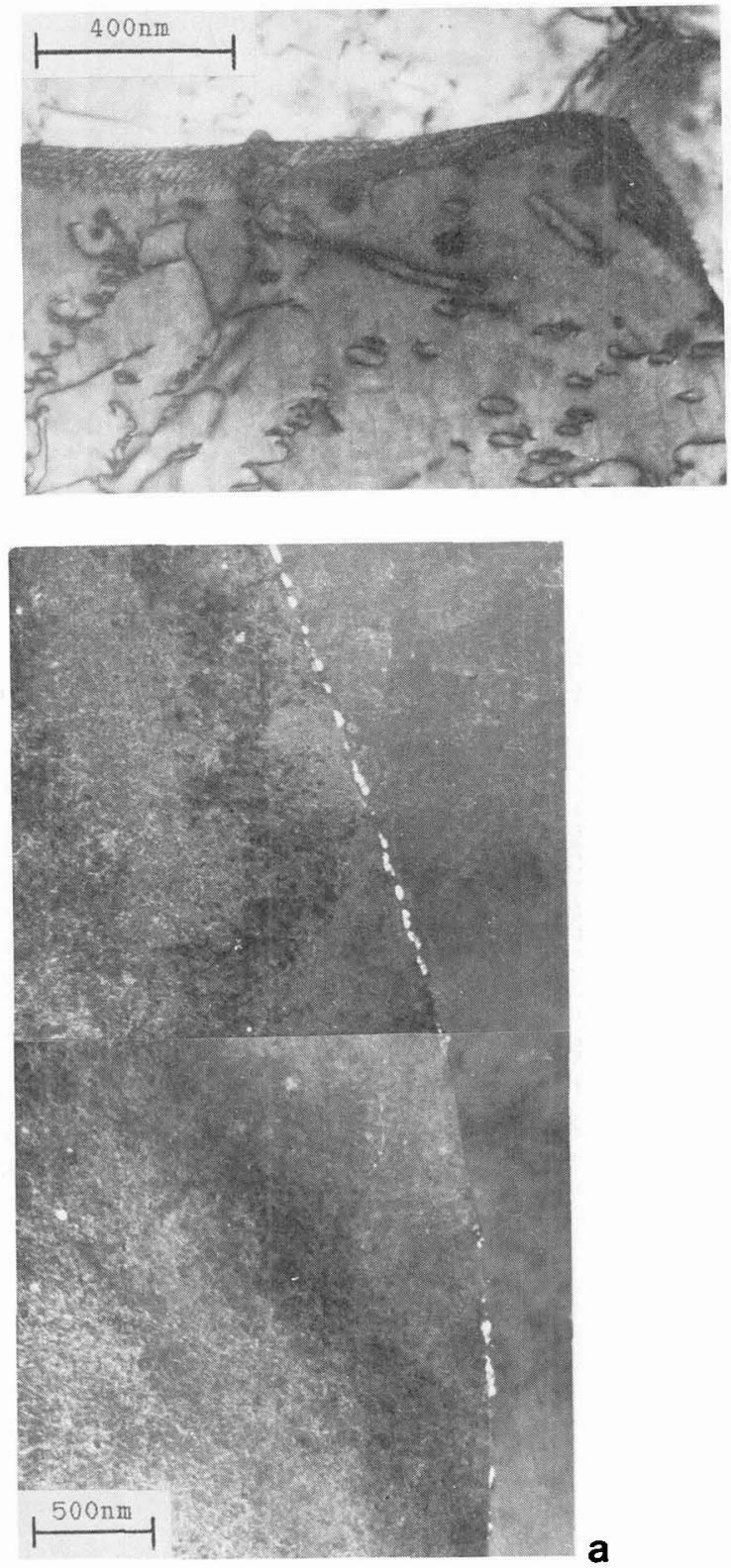

Figure 3: T.E.M. Bright field on grain boundary H.T. T3

Figure 4: T.E.M. Dark field intergranular precipitation

a) H.T.A

b) H.T. C

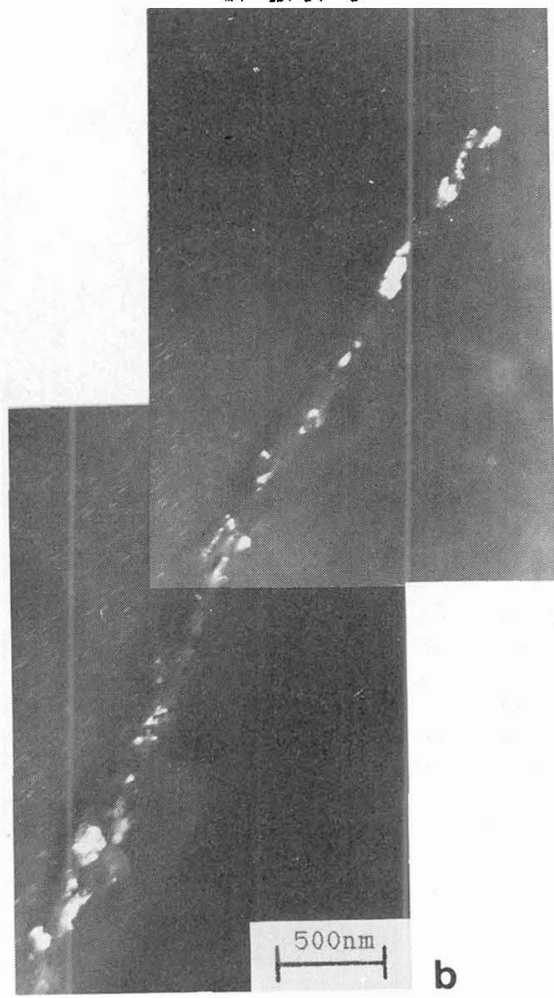



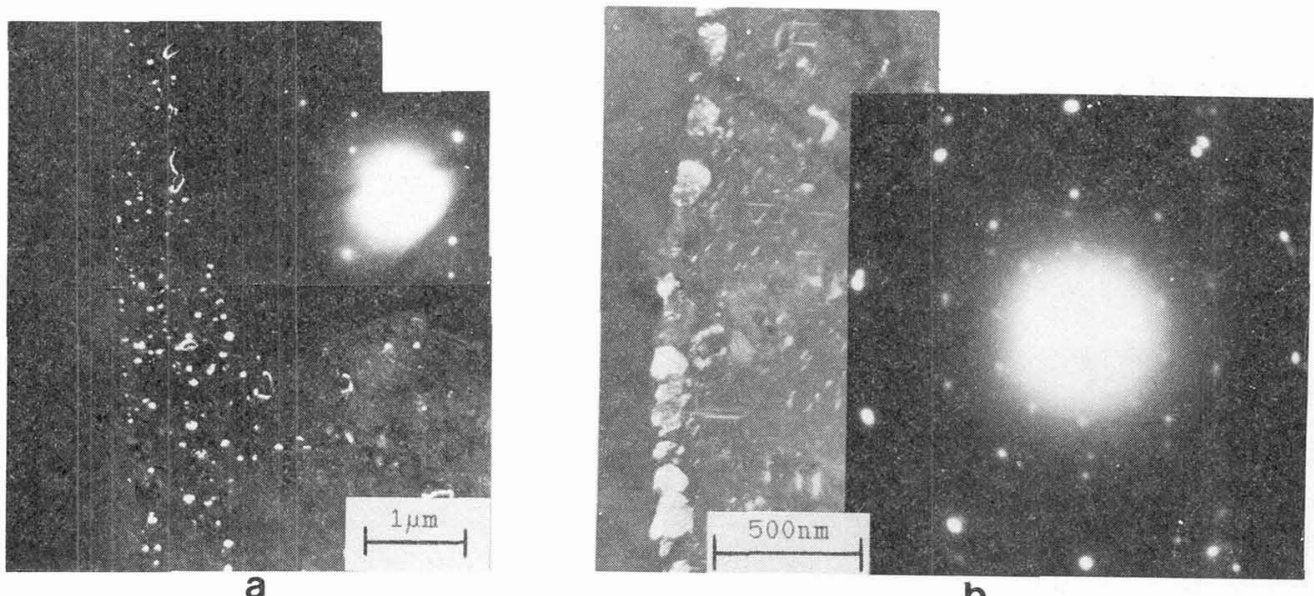

b

Figure 5:T.E.M. Intergranular precipitate identification, a) Dark field and diffraction pattern H.T. A . b) Dark field and diffraction pattern H.T. C.

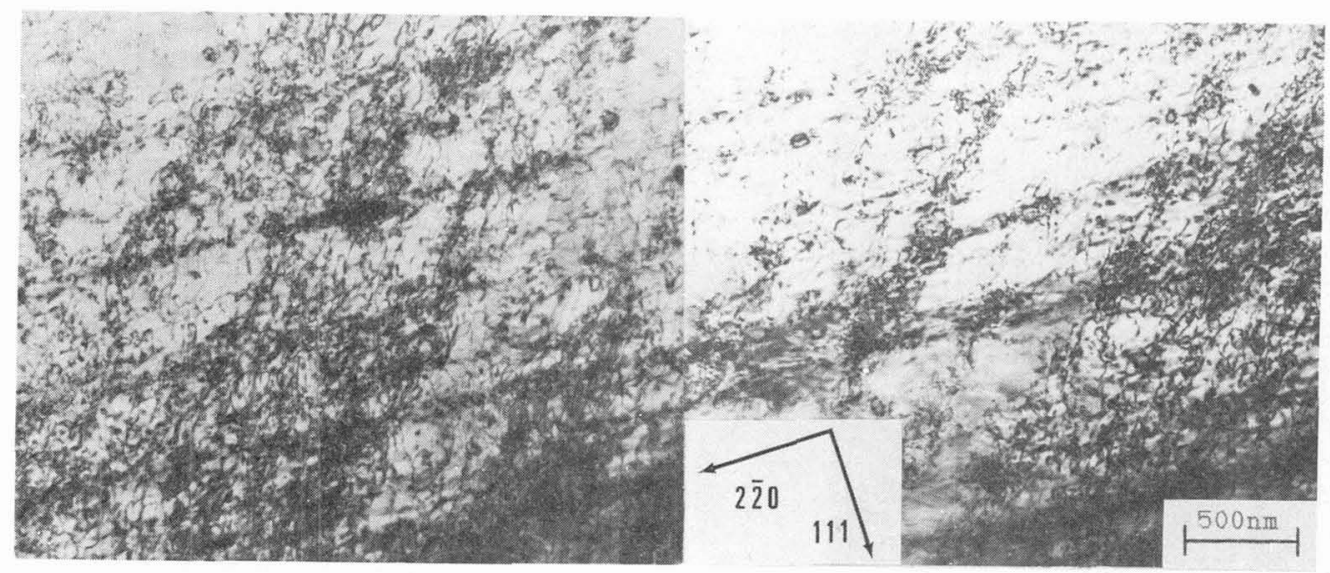

Figure 6.a:T.E.M. Bright fleld deformation modes $\epsilon \max$ H.T. T8

- Deformation modes

The study of deformation modes was carried out quantitatively and qualitatively. Quantitatively:results are sumarized in table 4 in terms of volume fraction of deformation bands; these results were obtained from [3] by optical microscopy on polished tensile samples.

Qualitatively: by T,E.M., to show the slip character, for every observation we put a (111) Slip plane close to the Bragg incidence, the diffracting vector was not parallel to the [111] direction, the obervations are shown on fig. 6 .

\begin{tabular}{|c|c|c|c|c|c|}
\hline$\epsilon=5 \%$ & $\begin{array}{l}f_{v} \\
\sigma\end{array}$ & $\begin{array}{c}\text { T3 } \\
0.16 \\
0.06\end{array}$ & $\begin{array}{c}\text { T8 } \\
0.26 \\
0.06\end{array}$ & $\begin{array}{c}A \\
0.14 \\
0.04\end{array}$ & $\begin{array}{c}c \\
0.16 \\
0.04\end{array}$ \\
\hline$\epsilon \max$ & $\begin{array}{l}f_{v} \\
\sigma\end{array}$ & $\begin{array}{l}0.31 \\
0.07\end{array}$ & & $\begin{array}{l}0.32 \\
0.07\end{array}$ & $\begin{array}{l}0.30 \\
0.05\end{array}$ \\
\hline
\end{tabular}

Table.4: Mean volume fraction of deformation bands(optical micrscopy), $0^{\circ}$ standard deviation. 


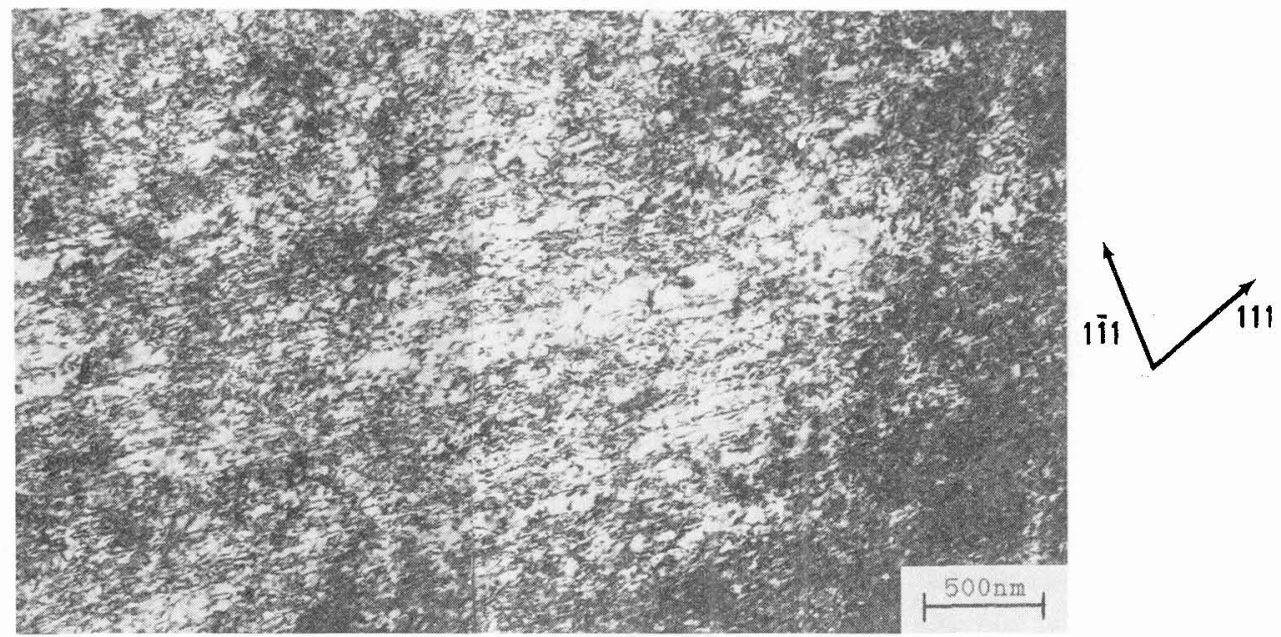

Figure 6.b:T.E.M. Bright field, deformation modes, emax H.I.C.

\section{DISCUSSION}

The trend which is emerging from the preceding results is a strong decrease in the toughness level at H.T. close to the peak aged condition. This toughness decrease is accompanied by a particular precipitation on grain boundaries and by a relative stability in deformation modes. The following discussion will focus on these microstructural aspects in order to explain the toughness evolution. To determine the role of this precipitate on the toughness level a study was conducted using fractography replicas of the fracture surfaces from tensile tests with heat treatment $A$ and $C$. These replicas show, in fig.7.a and $c$, that the fractured grain boundaries bear the trace of the intergranular phases; the main parameters obtained from the replicas are shown on table 5 .

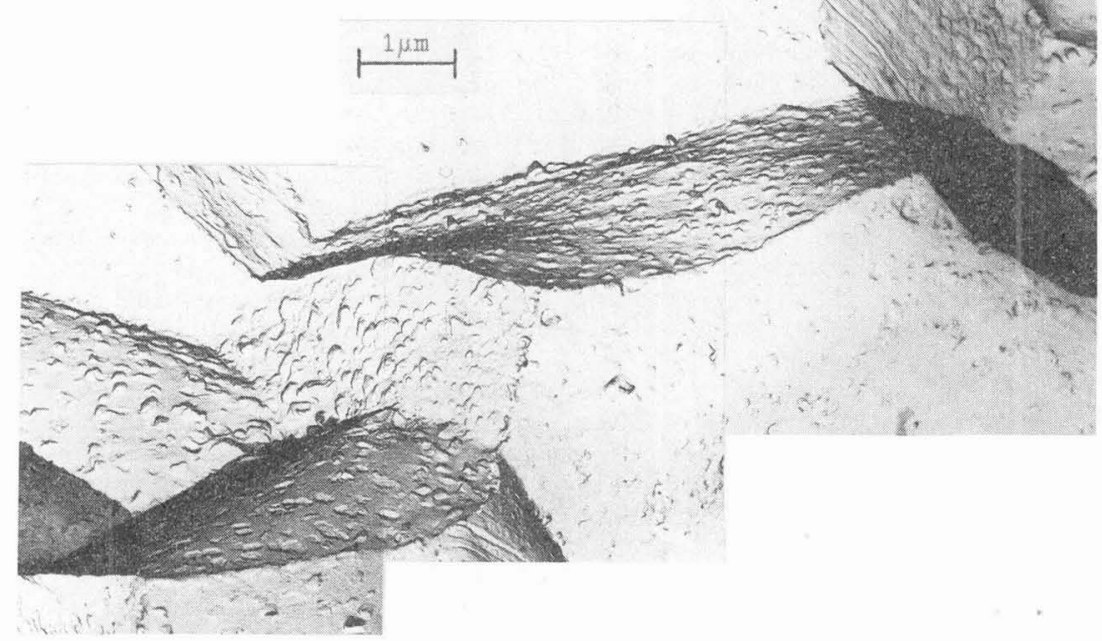

Figure 7.a: T.E.M. Replica, fracture modes tensile test H.T.C. 


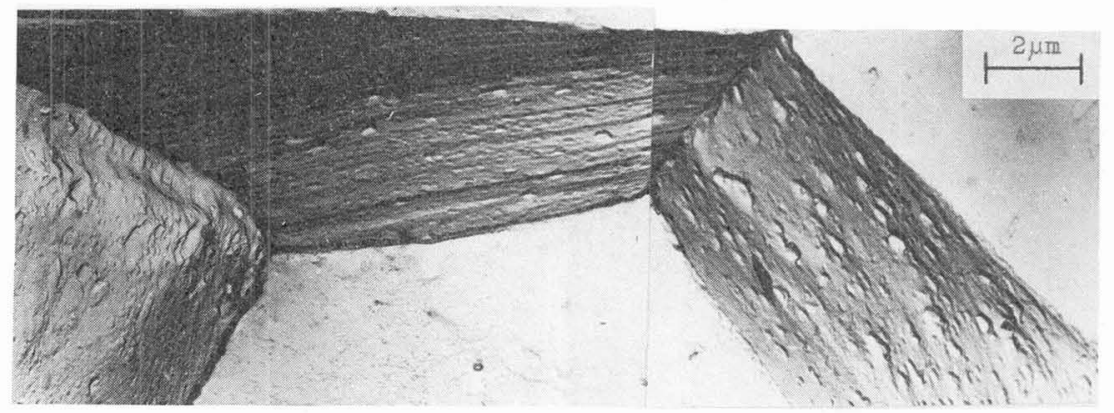

Figure 7. b:T.E.K. Replica, fracture modes tensile test H.T.A

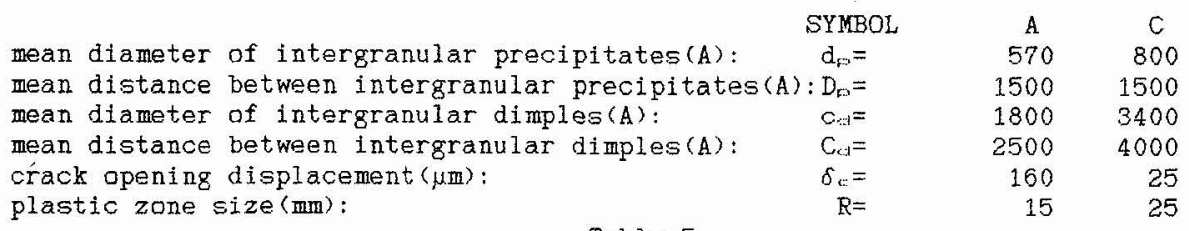

Table 5

$\delta_{\text {: }}$ and $\mathrm{R}$ were calculated with the following relations:

$$
\delta_{\mathrm{c}}=2 \mathrm{~K}_{\mathrm{e}} \mathrm{2} / \pi \mathrm{E} \sigma_{Y} \quad \mathrm{R}=1 / \pi\left(\mathrm{K}_{i} / \sigma_{\searrow}\right)=
$$

Table 5 shows that whatever the toughress value the size of the plastic zone (R) and the crack opening displacement $\left\langle\delta_{c}\right\rangle$ are substantially larger than the grain diameter. Furthermore, it appears that the parameters $\mathrm{D}_{\mathrm{F}}$ and $\mathrm{c}: \mathrm{l}$ are not correlated.

The examination of deformation modes has shown that the slip homogeneity increases with H.T. approaching the peak aged condition. Two main factors influence the slip character $1 . e$. the size of $\delta^{\prime}$ and the size of $S^{\prime}$ precipitates. For the complete $H . T$. the size of $\delta^{\prime}$ remains smaller than the critical size favouring localized deformation bands. Nevertheless other factors could spread the slip: Firstly, the Imposed strain level by multiplication of slip systems and secondly the presence of the more aged H.T. of GPB zones precursor of homogenous S' precipitates. It has been shown that GPB zones or ' $S^{\prime}$ precipitates in particular circumstances could be broken by dislocations (unpublished results: D. Khiredine, R. Rahouadj and M.Clavel). In our opinion the fact that homogeneous $S^{\prime}$ precipitates are scarce whatever $H . T$., could favour a by-passing process at high strains. Finally the relative homogeneity of slip is mainly governed by the amount of elongation avoiding the $\delta^{\prime}$ and/or the GPB zone effect on localized deformation modes.

It is clearly shown that the distance between slip bands by T.E.M. and by optical microscopy does not correspond. The same results arise by observing slip band emerging at the surface of the grain boundaries. These observations indicate that among slip bands in the matrix only a few of ther induce slip traces on the surfaces. We consider that the slip bands correspond to the first active slip planes during the strained process. If we want to understand the role of the slip character we must study the flrst stage of the deformation process i,e, for strains below $5 \%$. In other words optical quantative metallography would appear to be an inappropriate method for the quantification of slip gharacter if it is conducted at high strains. The difference observed in our results concerning the volume of slip 
bands between $5 \%$ strained and emax is mainly induced by the number of deformed grains rather than the multiplication of slip traces in the strained grains. In the first stage of deformation, only the grains oriented for easy glide are plastically strained. Other grains, particularly those oriented for multiple slip, would be plastically strained at a higher level of strain. However, multiple slip induces dislocations crossing favoring a multiplication of slip bands. In fact, only few grains would be fractured by interaction between slip bands and boundaries, the others are fractured by dimple formation around intergranular precipitates. These results indicate that the deformation modes exhibited by the 2091 alloy for heat treatment $T 3, T 8, A$ and $C$ play in our opinion, a minor role in the toughness decrease.

From the previous results.it clearly appears that toughness is mainly controlled by intergranular precipitation i.e. $S$ (Al_CuMg) for A H.T. and T2 for C H.T.. The grain boundaries for H.T. T3 and T8 remain free of precipitation. During the rupture process three stages are commonly considered [4], germination, growth and coalescence of dimples, using the preceding approach for intergranular failure; if we consider the size of grains and the extent of the highly strained zone (2$\left.\delta_{c}\right)$ at the crack tip, several grain boundaries are always highly strained in the plastic zone. In other words it is suggested that growth and coalescence processes do not actually intervene in the fracture process. In fact, initiation of voids is considered to be the main mechanism based on precipitate/matrix interface decohesion. The increase of ultimate stress noted from $H$. T. A to C could favour this decohesion. It would be noticed that coherency mismatch between $S$ phase and matrix would be smaller than those encountered between $T 2$ and the matrix, furthermore our observations demonstrate that the interface quasi crystal/matrix is mechanically weak. Careful examination of table 5 indicates that the mean distance between dimples does not correspond to the mean distance between precipitates, furthermore the growth rate of voids remains constant between $A$ and $C$ treatments and close to 4 considering the mean diameter of particles. This indicates that probably among the intergranular phases only the largest induced dimple formation [4][5]. The present discussion has been dealing only with intergranular failure as this phenomenon is obviously associated with toughness. decrease. Meanwhile ductile fracture exhibited by H. T. T3 and T8 samples is a well known process [4][6] governed by intermetallic compounds.

\section{CONCLUSTON}

The 2091 CP274 alloy exhibits a strong decrease of toughness (plane stress) associated with a transition of rupture modes from transgranular to intergranular. This toughness decrease appeared when the heat treatment approached peak aged conditions and is associated with the 1ntergranular precipitation of the quasi cristalline phase T2. In fact deformation modes or $\delta^{\prime}$ and $S^{\prime}$ precipitates play a minor role in the decrease of grain boundary strength and it is suggested that T2 quasi cristalline precipttates on frain boundartes is mainly responsible for the drastic toughness decrease observed in this alloy.

\section{ACKNOWLEDGMENTS}

We would like to thank the DRET organization for financial support and Dr.F Armanet for his helpful discussions and technical assistance.

\section{REFERENCES}

1 P.SAINFORT, B.DUBOST and P. MEYER Invited Paper European Materials Research Society Fall Meeting Councll of Europe, Strasbourg, France Nov, 26-28 1985

2 P.MEYER and B.DUBOST Aluminium Lithium III, Edited by C.BAKER, P.J.GREGSON

S.J.HARRIS and C.J.PEEL p. 37

3 R. RAHOUADJ, J.MENIGAULT and M. CLAVEL, to be published in Mater. Sci. Eng.

4 G.G.GARETT and J.F.KNOTT, Metall. Trans., Vol 9A Sept 1978-1187

5 A. K. VAZUDEVAN, E.A. LUDWICZAK, S.F. BAUMANN, P.R. HOWELL, R. D. DOHERTY and

M. M. KERSKER, Mat. Sc1. and Techn. Dec 1986 Vol 2-1205

6 D.ALIAGA Thesis, Université de Pottiers, U.E.R., EHSMA, 29 Nov 1978 